\title{
Improving qualitative parameters of LLC converter using a perspective semiconductor and magnetic components
}

\author{
Boris Kozacek, Michal Frivaldsky, Viliam Jaros \\ Department of Mechatronics and Electronics, University of Zilina \\ Institute of Electrical Engineering, University of Zilina \\ Zilina,Slovakia \\ michal.frivaldsky@fel.uniza.sk
}

\begin{abstract}
This paper has been realized in order to show simplified design procedure on how to meet the standards for dc-dc converters, which are being constantly increased. The paper deals with improvement of qualitative parameters of LLC converter. Using evaluations methods Figure of Merit, we select optimal components suitable for high-frequency applications with high power density, where we want elevate the significance of perspective of semiconductors $\mathrm{GaN}, \mathrm{SiC}$ and modern magnetic materials. The main advantage of using FoM assessment technique for certain system's components is the elimination of simulation and physical experiments for effectivity evaluation. In conclusion, a comparison of converter considering standards ENERGY STAR defining the efficiency parameters of the converter at different load is provided. After it also comparisons of the efficiency using diode rectifier and synchronous rectifier on the secondary site are given.
\end{abstract}

Keywords- figure of merit; power losses; CoolMOS; GaN; SiC; Magnetics materials, 3F4, 3F45, efficiency LLC converter;

\section{INTRODUCTION}

Demands on high efficiency and power density of electrical devices have been lately high. This is the reason why electronic components such as diodes, transistors and transformers are accentuated and why there was set the scientific discipline Figure of Merit (FoM) dealing with this problematics. FoM is in fact the non-dimensional quantity which serves as the qualitative indicator for electrical components: the lower the resulting FoM value is, the better is the qualitative parameter of semiconductors components [1]-[4].

One of the ways how to increase the qualitative parameters of power semiconductor system is the choice of optimal semiconductor components. Here we will consider the perspective semiconductor materials GaN and SiC. Another very important step to properties enhancement of a power semiconductor converter is the appropriate choice of magnetic materials and other components [5]-[8]. This paper deals with several ways that can be used to choose the optimal semiconductor components and a highfrequency transformer, which would be suited for standards specifications given for quality indicators of power supply. For that reason, it is necessary to choose the appropriate material which would be the transformer made of. For that purpose several magnetic materials used for transformers operating in high switching frequencies are analysed.

The magnetic material plays a major role in the design of magnetic components. The choice of design of magnetic material is based on three basic criteria of the transformer and the price, size and performance. Currently, the proposed magnetic components operate in frequencies at several megahertz. For this purpose magnetic material such as silicon steel, iron-nickel alloy, cobalt-iron amorphous alloys and ferrites is used.

Ferromagnetic cores are also manufactured in the form of powder monopermalloy, sendust, or in the form of powder iron core. Of these magnetic materials are defined magnetic properties required for the design of inductive components such as the value of saturation induction $\mathrm{B}_{\mathrm{SAT}}$, permeability $\mathrm{u}_{\mathrm{i}}$ resistance $\rho$, core loss, thermal conductivity, magnetic remanence $\mathrm{Br}$ and coercivity $\mathrm{Hc}$ (coercive force).

In the design of inductive components the core loss represents one of the most important parameters. Core loss can be influenced bz the selection of suitable material.

Using the techniques mentioned above, it is possible to design switched mode power supplies (SMPS) with perspective converter's structure LLC, which would be suited to upcoming standard specifications called ENERGY STAR.

Another method to increase the efficiency of the converter is to replace the diode rectifier with synchronous rectifier. However, this solution is complicated, because transistors need to be controlled, which is a problem at high switching frequency. The solution is a LLC converter with primary or secondary current self-driven synchronous rectifier [9].

The main electrical parameters of proposed converter of LLC topology, which shall be suited for distributed power systems and will be investigated within this paper, are:

$\begin{array}{ll}- & \mathrm{U}_{\mathrm{IN}}=390 \mathrm{~V} \\ - & \mathrm{U}_{\text {OUT }}=48 \mathrm{~V} \\ - & \mathrm{I}_{\text {OUT }}=20 \mathrm{~A} \\ - & \mathrm{f}_{\mathrm{SW}}=1 \mathrm{MHz}\end{array}$




\section{Evaluation of FOM of Selected DiOdes AND TRANSISTORS}

Comparisons of several generations of different types of semiconductor structures are given here. FoM parameter for selected diodes were calculated for Si diode IDP15E65D1, which is reverse recovery type thus envisaged $\mathrm{Q}_{\mathrm{rr}}$ charge was considered. For $\mathrm{SiC}$ diodes with no reverse recovery only charge $\mathrm{Q}_{\mathrm{c}}$ was considered [10]-[11].

TABLE I. FIGURE OF MERIT For Diode

\begin{tabular}{|l|r|r|r|r|}
\cline { 2 - 5 } \multicolumn{1}{c|}{} & $\mathbf{Q}_{\mathbf{c}}[\mathbf{u C}]$ & $\mathbf{Q}_{\mathbf{r r}}[\mathbf{u C}]$ & $\mathbf{V}_{\mathbf{f}}$ & FoM $\left[\mathbf{Q}_{\mathbf{c}} * \mathbf{V}_{\mathbf{f}}\right]$ \\
\hline IDP15E65D1 & & 0,37 & 1,35 & 0,4995 \\
\hline IDH12G65C5_SiC & 0,018 & & 1,5 & 0,027 \\
\hline UJD06510T_SiC & 0,016 & & 1,5 & 0,024 \\
\hline IDH20G65C5_CoolSiC & 0,029 & & 1,5 & 0,0435 \\
\hline SCS220AG-SiC & 0,031 & & 1,35 & 0,04185 \\
\hline IDW20G65C5-SiC & 0,029 & & 1,35 & 0,03915 \\
\hline
\end{tabular}

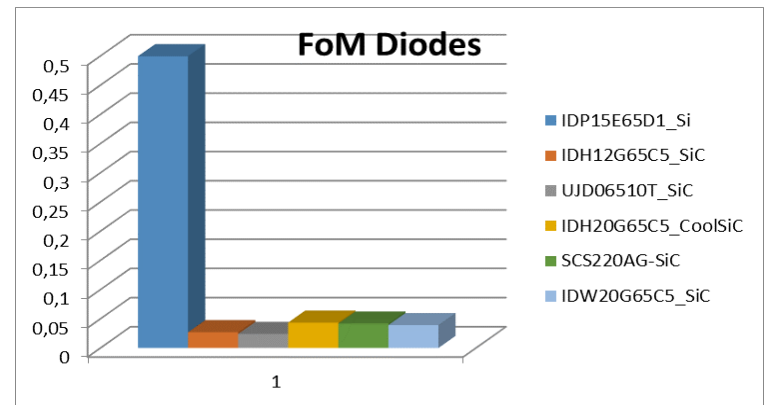

Figure 1. FoM evalution for diodes

The evaluation of selected transistors was done for hard-switching commutation mode, as well as for ZVS mode. Different types were evaluated, whereby we focused on best in class transistors, which are nowadays available on the market. These are CoolMOS $\mathrm{SiC}$ and $\mathrm{GaN}$ transistors. As was already mentioned, if we need to evaluate selection of transistor more complexly, then it is necessary to consider also gate drive loss KGS. This part becomes very important when very-high frequency operation is considered [12].

When we know the datasheet values of parameters which are necessary for determination of $\mathrm{K}_{\mathrm{GS}}$ and Kloss, then we can calculate the $\mathrm{FOM}_{\mathrm{HS}}$ and $\mathrm{FOM}_{\mathrm{ZvS}}$ which are listed in Table II.

TABLE II. FIGURE OF MERIT FOR HARD AND SOFT SWITCHING

\begin{tabular}{|l|c|c|c|c|}
\cline { 2 - 5 } \multicolumn{1}{c|}{} & $\mathrm{K}_{\mathrm{GS}}$ & FOM $_{\mathrm{HS}}$ & $\mathrm{K}_{\text {loss }}$ & FOM $_{\mathrm{ZvS}}$ \\
\hline IPW60R165CP & 1,098 & $\mathbf{3 , 4 3 3}$ & 1,013 & $\mathbf{3 , 3 1 7}$ \\
\hline SPP20N60C3 & 1,29 & $\mathbf{8 , 9 6 6}$ & 1,203 & $\mathbf{8 , 7 8 5}$ \\
\hline SiC 2N7638-GA & 1,25 & $\mathbf{5 , 7 3 7}$ & 1,033 & $\mathbf{5 , 3 3 2}$ \\
\hline GaN EPC2027 & 1,177 & $\mathbf{0 , 3 8 2}$ & 1,09 & $\mathbf{0 , 3 6 1}$ \\
\hline GaN GS66506T & 1,128 & $\mathbf{0 , 2 4 3}$ & 1,071 & $\mathbf{0 , 2 3 9}$ \\
\hline GaN GS66508T & 1,128 & $\mathbf{0 , 2 4}$ & 1,02 & $\mathbf{0 , 2 3 2}$ \\
\hline GaN GS66508P & 1,128 & $\mathbf{0 , 2 4 7}$ & 1,071 & $\mathbf{0 , 2 4 1}$ \\
\hline
\end{tabular}

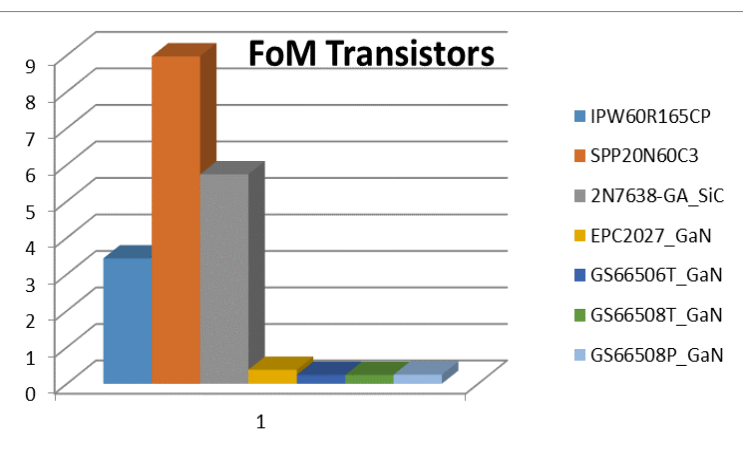

Figure 2. FoM evalution for transistors

As can be seen, the lowest value of FOM parameter is for GaN transistor GS66508T (the lower the value is the better performance of transistor may be achieved). The hard switching performance was already done, whereby detailed information can be seen at [13][16]. The relevancy of FOM parameter will be finally evaluated in the way of efficiency (one of qualitative indicator) investigation of proposed LLC converter.

\section{Evaluation of Selected Magnetics MATERIALS}

\section{A. Magnetics materials}

When selecting a material suitable for the chosen application domain, we must take into account the parameters listed in Table III.

TABLE III. PARAMETERS FOR DIFFERENT MATERIALS

\begin{tabular}{|c|c|c|c|c|c|c|}
\hline Material & $\begin{array}{c}\text { Bsat } \\
(\mathrm{mT})\end{array}$ & $\mu \mathrm{i}$ & $\begin{array}{c}\rho \\
(\Omega . \mathrm{m})\end{array}$ & $\begin{array}{c}\mathrm{Tc} \\
\left({ }^{\circ} \mathrm{C}\right)\end{array}$ & $\begin{array}{c}\text { Thermal } \\
\text { conductivity(W/(m.K)) }\end{array}$ & $\begin{array}{c}\text { Frequency } \\
\text { range(MHz) }\end{array}$ \\
\hline 3F3(MnZn) & 440 & 2000 & 2 & $>200$ & $3,5^{\sim} 5$ & $0,2-0,5$ \\
\hline 3F35(MnZn & 500 & 1400 & 10 & $>240$ & $3,5 \sim 5$ & $0,5-1$ \\
\hline $3 F 4(\mathrm{MnZn})$ & 410 & 900 & 10 & $>220$ & $3,5 \sim 5$ & 1.2 \\
\hline 3 F45(MnZn) & 420 & 900 & 10 & $>300$ & $3,5^{\sim} 5$ & 1.2 \\
\hline
\end{tabular}

, where

- $\quad B_{\text {sat }}$ is saturation induction

- $\quad \mu_{\mathrm{i}}$ is initial permeability

- $\quad \rho$ is the electrical resistance

- $\quad T_{c}$ is the Curie temperature

Based on the values form the table above, several materials appropriate for $1 \mathrm{MHz}$ frequency were chosen Selected materials and their frequency characteristics is necessary to determine the value of the saturation induction $\mathrm{B}_{\max }$ (Fig. 3). For all materials the value of excitation will be the same. It is then possible to compare the converter's efficiency during the change of the transformer core material. The value $\mathrm{B}_{\max }$ is selected to be the saturation limit of the transformer so as not to exceed the maximum magnetic flux density. 


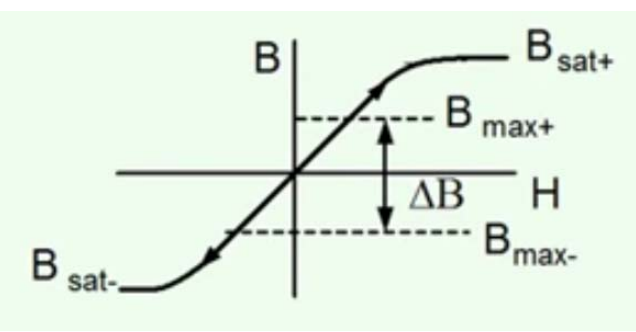

Figure 3. Saturation characteristic of transformer

Dependence of saturation induction on frequency and temperature for materials $3 \mathrm{~F} 3-3 \mathrm{~F} 45$ can be seen on characteristic of selected materials in next datasheets (Fig. 4). The higher the operating frequency the lower the value of saturation induction and the increase of the core loss value is achieved.

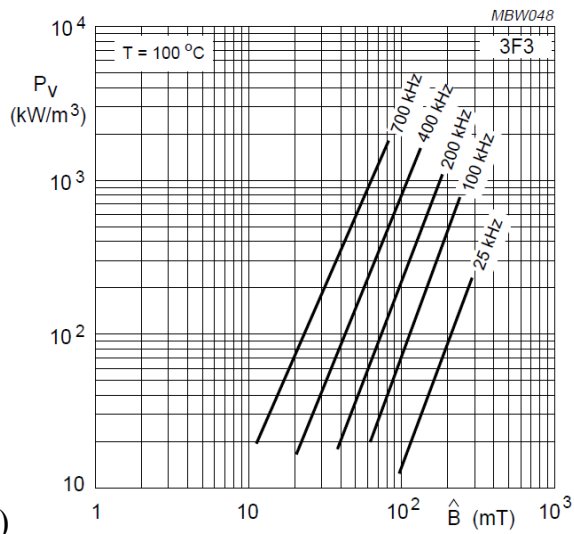

a)

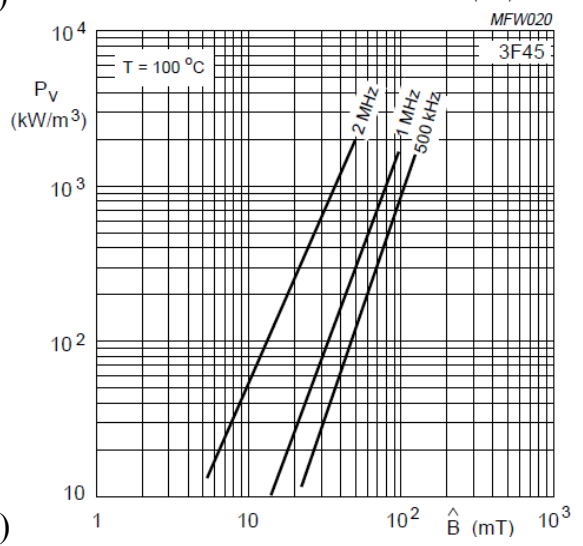

Figure 4. a),b) Specific losses of ferrite cores in relation with saturation, frequency and temperature

Let's consider the core's temperature about $60^{\circ} \mathrm{C}$, which indicates that the value of maximal saturation induction is $\mathrm{B}_{\max }=14 \mathrm{mT}$, and in case of doubleacting converters the induction rise is $\Delta \mathrm{B}=28 \mathrm{mT}$. As it can be seen in Fig. 4 , for value of $\Delta B=28 \mathrm{mT}$ the volume losses for material $3 \mathrm{~F} 45$ are much lower comparing to all other generations of materials. This assumes that this material will be the most appropriate when considering improved qualitative indicators of power supplies.

In Fig. 5 the interpretation of FoM parameter of ferrite materials can be seen. It is represented by the product of operating frequency and saturation induction. When comparing, it is obvious that the most optimal choice for parameters of target application are the materials 3F4 and 3F45. Materials $3 \mathrm{~F} 5$ and $4 \mathrm{~F} 1$ are not available for higher performance.

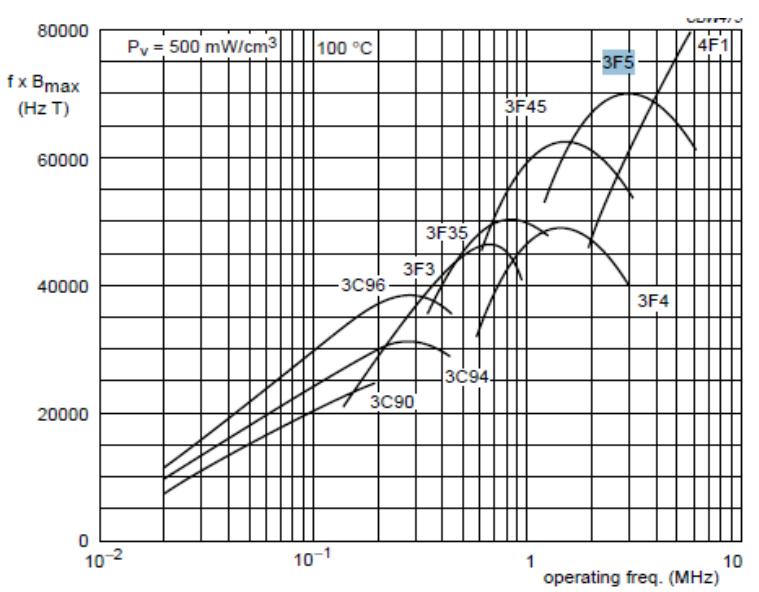

Figure 5. FoM parameter for selected ferrite materials

\section{B. Selection of core dimensions}

One of the ways how to select the correct size of the core is to calculate it using the following equations. It is considered to define the area needed for the winding:

$$
A_{w}=\frac{2+N 1+I_{r m s}}{I * k}
$$

It is also necessary to calculate the effective core area $A_{e}$ by the following equation:

$$
A_{\theta}=\frac{U 1 * D_{O N}}{N 1 * f+\Delta B}
$$

For these relations it is necessary to know the number of turns on the primary side of the transformer. The second option is to calculate the minimum area of the core $A_{p}$, Which is equal to the product of the area $A_{e}$ of the core and the winding area $A_{w}$. Once we have determined the value of $\Delta B$, then based on the following formula it is possible to calculate the minimum area of core $A_{p}$ :

$$
\begin{aligned}
& A_{p}=A_{e} * A_{w} \\
& A_{P}=\frac{\left(U 1 * D_{Q N}\right) * 2+l_{r m w}}{f_{P} * \Delta B * \pi * k}
\end{aligned}
$$

, where

- J current density

- $\quad \mathrm{k}$ fill factor

Based on the values of the minimum core area $A_{p}$ necessary for the proper transformer operation, we can choose the manufacturer's catalog suitable type core for the required operating frequency and the required power.

After selecting a transformer, we compared the selected type of core made of different materials in terms of the converter's efficiency investigation, as can be seen in the next chapters. 


\section{Evaluation Power Losses of Selected MATERIALS FOR CORE TRANSFORMER}

Before the evaluation of core losses, it is necessary to choose the specific type of core which would be suited for designed LLC converter. The minimal area of a core $A_{p}$ for $\Delta B=28 \mathrm{mT}$ was computed from the relationship (4):

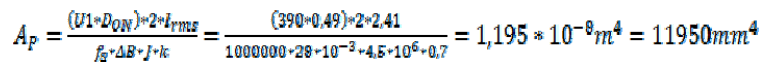

This condition satisfies the core EQ38/8/25 (chosen from the producers' catalogue) with effective volume $7,9 \mathrm{~cm}^{3}$, which can be made of all selected materials. After this, the core losses depending on the type of material should be analysed. Following value of power losses in core (for volume in $\mathrm{cm}^{3}$ ) are given in datasheets.

$$
\begin{array}{ll}
\mathrm{Kfe}_{3 \mathrm{~F} 3}=9 \mathrm{~W} / \mathrm{cm}^{3} & \mathrm{Kfe}_{3 \mathrm{~F} 35}=3 \mathrm{~W} / \mathrm{cm}^{3} \\
\mathrm{Kfe}_{3 \mathrm{~F} 4}=0,1 \mathrm{~W} / \mathrm{cm}^{3} & \mathrm{Kfe}_{3 \mathrm{~F} 45}=0,06 \mathrm{~W} / \mathrm{cm}^{3}
\end{array}
$$

As we can see the highest losses in core for material $3 \mathrm{~F} 3$ are much higher than preferred material 3F45. Next section verifies this claiming by simulation model, where the material of core of transformer is changed in designed converter.

\section{SimULATION ANALYSIS OF FOM IMPACT ON CONVERTER'S EFFICIENCY}

Simulation analyses were realized on the proposed resonant LLC converter, where ZVS commutation mode is achieved. We did not use GaN transistors on the primary side due to fact that PSPICE models do not exist or aren't properly defined. Then the problems with convergence and consequently simulation accuracy arise. These semiconductors components will be verified in the experimental way on the physical model of converter (in full paper).

In order to verify proposed FoM evaluation methodology, we provided investigation with very accurate simulation models of CoolMOS IPW60R165CP (primary side of converter) with Schottky SiC UJD06510T (secondary side), which both exhibit the best FoM assumption.

Within efficiency investigation we were changing the transformer core magnetic properties. Also ideal ideal coupling $\mathrm{K}$ linear $=1$ of transformer was investigated in order to have reference value. Then we compared the core material $3 \mathrm{~F} 3$ and $3 \mathrm{~F} 45$.

Based on the results can be seen (fig. 6), that converter achieves the highest referenced efficiency when core material $3 \mathrm{~F} 45$, which is considered as the best alternative for transformer core material.

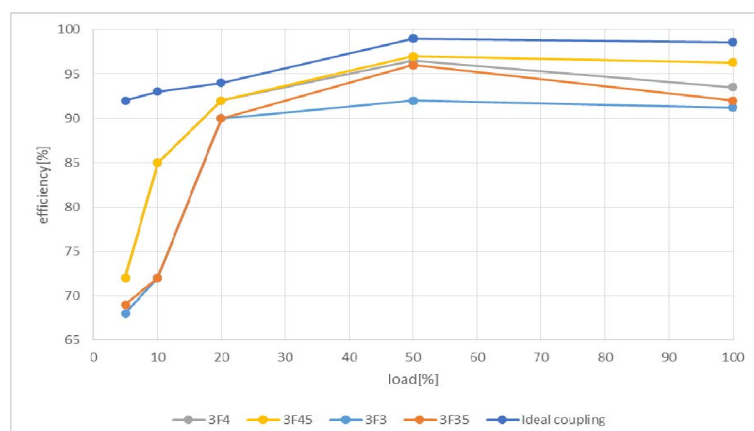

Figure 6. Converter's efficiency for various materials of core of transformer

\section{SimUlation ANALYSIS OF THE EFFICIENCY CONSIDERING SYNCHRONOUS RECTIFIER}

When drawing up of the synchronous rectifier we will use transistors GaN structure EPC2001C and EPC2010C, which have current and voltage stress comparable to Schottky diodes. On the Fig.7 we can see a significant reduction of power losses using synchronous rectifier. The lowest power losses are presented in the case of transistor EPC2001C.

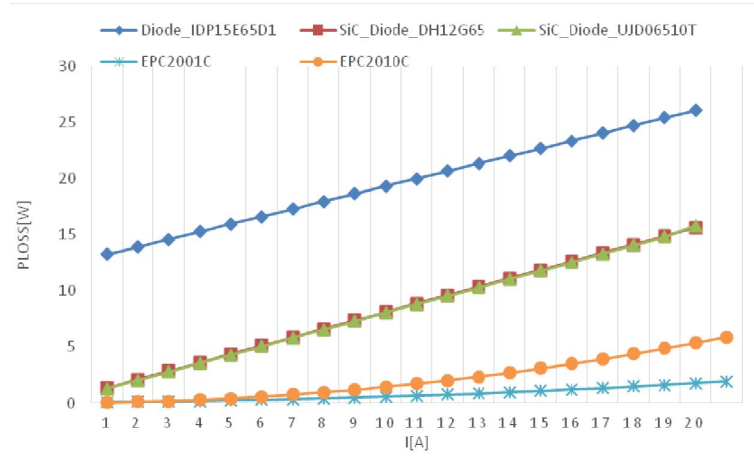

Figure 7. Switching losses of diodes and transistors for changing the current load in the range from 1-20 $\mathrm{A}$ and for frequency $1 \mathrm{MHz}$

This transistor was then used in synchronous rectifier, which was implemented into the proposed LLC converter. The result is increase of efficiency of the converter by about $1.3 \%$ across the full operation range of converter fig. $8 \mid$.

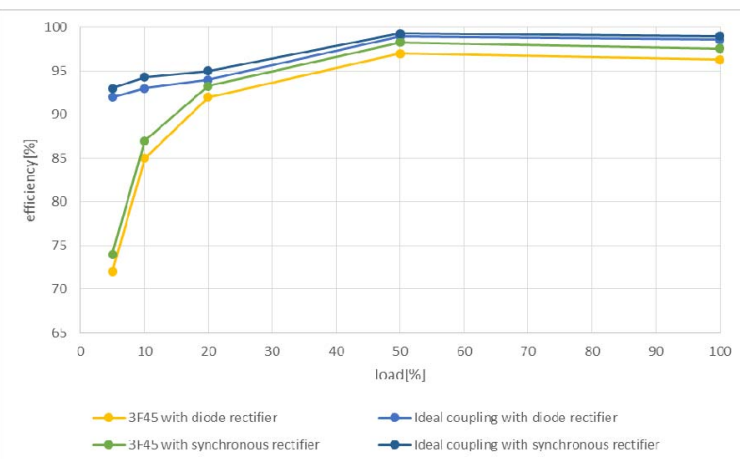

Figure 8. Converter's efficiency for various type of output rectifier 


\section{CONCLUSION}

Aim of this paper was to summarize the important knowledge for possibility of increasing of the qualitative parameters of LLC converter. Selected components underwent the FoM analysis and their appropriateness for certain application was compared. The analytical and simulation results confirmed the significant progress of GaN technology in case of switching components. This technology minimizes the values of parasitic elements and is suitable for high switching frequencies as well as it decreases the power losses. Other task was to compare the diodes with silicon structure and silicon carbide. In this case we found out that the $\mathrm{SiC}$ diodes do not have reverse recovery and so their power losses are significantly lower depending on the current load. Further analysis aimed to proper selection of core material for transformer. A huge progression of novel materials was found out - such materials are for example $3 \mathrm{~F} 4$, 3F45 with suitable properties for higher performance

\section{REFERENCES}

[1] B. Kozacek, M. Frivaldsky, J. Kostal, M. Piri, "Figure of Merit of Semiconductor Structures, Determination of impact on the system efficiency of LLC converter" 20th International Conference : Czech Repiblic, September 8-10,2015

[2] G. Deboy, N. Marz, J. P. Stengl, H. A. S. H. Strack, J. A. T. J. Tihanyi, and H. A. W. H. Weber, "A new generation of high voltage MOSFETs breaks the limit line of silicon," in Electron Devices Meeting, 1998. IEDM '98 Technical Digest., International, 1998, pp. 683-685.

[3] Jerry L.Hudgins, Grigory S.Simin etc, "An assessment of wide bandgap semiconductors for power devices," IEEE Transactions on Power Electronics, Vol.18, No.3, May 2003

[4] P.Spanik, R.Sul, M. Frivaldsky, P. Drgona ,J Kandrac :Performance investigation of dynamic characteristics of power semiconductor Diode. In:Electronics and Electrical Engineering. - Kaunas: Technologija, 2010. - No. 3(99). - P.36.

[5] B. Lu, W. Dong, Q. Zhao, and F. C. A. L. F. C. Lee, "Performance evaluation of CoolMOS/sup /spl trade// and $\mathrm{SiC}$ diode for single-phase power factor correction applications," in Applied Power Electronics Conference and Exposition, 2003. APEC '03. Eighteenth Annual IEEE, 2003, pp. 651-657 vol.2.

[6] I. Kim; S. Matsumoto, T. Sakai and T. Yachi, "New power device figure of merit for high-frequency applications," Proc. Power Semiconductor Devices and ICs, 1995, pp. 309-314.

[7] Jess Brown, Guy Moxey, "Power MOSFET Basics:Understranding MOSFET Characteristiks Associated With The Figure of Merit," Vishay Siliconix, 8.sep.2003.

[8] Johan Strydom, "eGaN(tm) - Silicon Power Shoot-Out:Part1 Comparing Figure of Merit(FOM), 1.sep.2010

[9] Yuan Bo, XU Ming, YANG Xu, Li Donghao : A new structure of LLC with primary current driven synchronous rectifier, Power Electronics and Renewable Energy Research Centerm Xi'an Jiaotong University, Xi'an, China, Center for Power Electronics Systems, Virginia Polytechnic Institute and State University, Blacksburg, USA, April 2010

[10] M. Frivaldsky,"Topologicka optimalizácia LLC Meniča," Univerzita of Zilina,2013 and frequency. And in conclusion, we compared the converter efficiency in the use of diode rectifiers with synchronous rectifier, where we recorded increase the efficiency of the converter. The efficiency converter was also verified when changing the materials of its core transformer and so we confirmed, that with magnetic materials $3 \mathrm{~F} 4$ and $3 \mathrm{~F} 45$ the converter suits the upcoming standard specifications ENERGY STAR. In final paper, these knowledge will be also supported by the experimental verifications.

\section{ACKNOWLEDGMENT}

The authors wish to thank to Slovak grant agency VEGA for project no. 1/0558/14 - Research of methodology for optimization of lifetime of critical components in perspective electronic appliances through the use of system level simulation.

[11] M. Frivaldský, P. Drgoňa, P.Špánik,: Experimental analysis and optimization of key parameters of ZVS mode and its application in the proposed LLC converter designed for distributed power system application, In: Electrical Power and Energy Systems. - ISSN 0142-0615. - Vol. 47. s.448 - 456

[12] M. Frivaldský, P. Drgoňa, P.Špánik,.: Hard switching process optimization for selected transistor suited for high power and high frequency operation, In: Journal of energy and power engineering. - ISSN 1934-8975. - Vol. 4, No. 12

[13] P. Špánik, M. Frivaldský ,P. Drgoňa,J. Kandráč,: Efficiency increase of switched mode power supply trough optimization of transistor's commutation mode, In: Electronics and electrical engineering = Elektronika ir elektrotechnika. - ISSN 1392-1215. - No. 9 (105) (2010), s. 49-52.

[14] V. Kindl, T. Kavalir, R. Pechanek, B. Skala, J Sobra, : "Key construction aspects of resonant wireless low power transfer system," ELEKTRO, 2014 , vol., no., pp.303,306, 19-20 May 2014

[15] P. Brandstetter, P. Chlebis,P. Palacky,: Application of RBF network in rotor time constant adaptation, In: Elektronika IR elektrotechnika, Issue:7, pp.21-26, 2011.

[16] L. Grman, M. Hrasko, J. Kuchta,: Single phase PWM rectifier in traction application, In: Journal of electrical engineeringelektrotechnicky casopis, Vol: 62, Issue:4, pp. 206 - 212, August 2011

[17] Z Ferkova, M. Franka, J. Kuchta,: Electromagnetic design of Ironless Permanent Magnet Synchronous Linear motor, In: International symposium on power electronics, electrical drives, automation and motion (SPEEDAM), Italy, June 1113, 2008, pp. 721-726.

[18] I. Kovacova, D. Kovac,: Inductive coupling of power converter's EMC, In: Acta polytechnica hungarica, Vol:6, Issue:2, pp. 41-53, 2009

[17] B. Dobrucký, P. Špánik, M. Kabašta : power electronics two phase Ortogonal system with HF input and Variabile Output, In : Electronics and Electronical Enginnering No.1 (89 Kanaus 2009, pp. 9-14, ISSN 1392-1215

[18] B. Dobrucký, M. Kabašta, P. Špánik :Using Complex Conjugated Magnitudes - and Orthogonal Park/Clarke Transformation Metods of DC/AC Frequency Converter, In: Electronics and Electrical Engineering No.5 (93), Kaunas 2009, pp. 29-34 